(c) American Dairy Science Association, 2004.

\title{
Ruminal Biohydrogenation in Holstein Cows Fed Soybean Fatty Acids as Amides or Calcium Salts
}

\author{
F. P. Lundy, III, ${ }^{1, \star}$ E. Block, ${ }^{2}$ W. C. Bridges Jr., J. A. Bertrand, ${ }^{1}$ and T. C. Jenkins ${ }^{1}$ \\ ${ }^{1}$ Department of Animal and Veterinary Sciences, Clemson University, Clemson, SC 29634 \\ ${ }^{2}$ Church \& Dwight Co., Inc., Princeton, NJ 08543 \\ ${ }^{3}$ Department of Experimental Statistics, Clemson University, Clemson, SC 29634
}

\section{ABSTRACT}

Fatty amides of high oleate fats and calcium salts of palm oil were reported to resist biohydrogenation by ruminal microorganisms. This study was conducted to determine whether converting polyunsaturated fat sources to amides and calcium salts had equal ability to resist biohydrogenation. A total mixed ration consisting of forage and concentrate contained (dry basis): 1) $2.45 \%$ soybean oil (SBO), 2) $2.75 \%$ calcium salt of SBO, 3) $2.75 \%$ amide of SBO, or 4) $2.75 \%$ of a mixture of the calcium salt and amide (80:20, wt/wt) of SBO. The 4 diets were fed ad libitum to 4 multiparous lactating Holstein cows fitted with ruminal cannulas in a $4 \times 4$ Latin square with 21 -d periods. Omasal samples were taken to measure postruminal fatty acid content and determine the extent of ruminal biohydrogenation. Adding SBO to the diets as either calcium salts or amides increased omasal flow of C18:2 (n-6) from 25 to $39 \mathrm{~g} / \mathrm{d}$. Omasal flow of C18:1 increased from 36 to 49 $\mathrm{g} / \mathrm{d}$ when $\mathrm{SBO}$ was fed to cows as calcium salts, but increased to $86 \mathrm{~g} / \mathrm{d}$ when SBO was fed as amides. Adding the soybean amide to the diet more than doubled the delivery of C18:1 (n-9) to the omasum of lactating cows, but it also increased trans fatty acid production in the rumen accompanied by milk fat depression. In this study, calcium salts and amide derivatives of fatty acids were both effective in enhancing omasal flow of unsaturataed fatty acids in lactating dairy cows. Amides were more effective than calcium salts for increasing the postruminal flow of oleic acid.

(Key words: biohydrogenation, calcium salt, fatty acyl amide, omasal sample)

Abbreviation key: AMD = amide of SBO added at $2.75 \%$ of DM, CAS = calcium salt of SBO added at $2.75 \%$ of DM, MIX = mixture of the calcium salt and

Received September 18, 2003.

Accepted December 1, 2003.

Corresponding author: T. C. Jenkins; e-mail: tjnkns@clemson.edu

*Present address: Department of Animal \& Nutritional Sciences, University of New Hampshire, Durham 03824. amide $(80: 20, \mathrm{wt} / \mathrm{wt})$ of SBO added at $2.75 \%$ of DM, SBO $=$ soybean oil .

\section{INTRODUCTION}

Jenkins et al. (1996) examined the ability of a fatty acyl amide, made by reacting butylsoyamide with soybean oil (SBO), to resist biohydrogenation and increase linoleic acid content in milk fat without disrupting ruminal fermentation. Results of this trial showed that amide of SBO increased linoleic acid percentage in milk when compared with SBO alone (6.28\% vs. $4.77 \%)$. The same trial by Jenkins et al. (1996) also showed that SBO disrupted ruminal fermentation as shown by a depression in acetate:propionate, which was avoided when the SBO was converted to an amide. Later research conducted with fatty acyl amides (Jenkins, 1998) focused on protecting oleic acid. By feeding oleamide to Holstein cows, Jenkins (1998) was able to increase the percentage of oleic acid in milk fat compared with feeding canola oil or the control diet (48.2, 35.1, and $23.2 \%$ of total fatty acids), respectively.

Calcium salts of palm fatty acids also were reported to resist biohydrogenation (Klusmeyer and Clark, 1991; Wu et al., 1991), which subsequently led to the feeding of a variety of fat sources as calcium salts to increase milk concentration of specific fatty acids such as CLA (Giesy et al., 2002) or oleic acid (Chouinard et al., 1997). However, feeding calcium salts of soybean and linseed oils to lactating cows failed to enhance milk concentrations of their most abundant fatty acids, namely linoleic and linolenic acids, respectively (Chouinard et al., 1998). Therefore, protection from ruminal biohydrogenation has not been established for calcium salts of unsaturated fat sources as it has for calcium salts of palm fatty acids.

The objective of this study was to compare the relative effectiveness of fatty acyl amides vs. calcium salts of SBO in enhancing the delivery of unsaturated fatty acids to the omasum of lactating Holstein cows. Because calcium salts may protect unsaturated fatty acids by encapsulating them within a water-insoluble matrix (Fotouhi and Jenkins, 1992), protection from biohydro- 
Table 1. Fatty acid composition of fat supplements used in diets fed to Holstein cows.

\begin{tabular}{lcccc}
\hline & \multicolumn{4}{c}{ Fat supplement ${ }^{1}$} \\
\cline { 2 - 5 } & SBO & MIX & CAS & AMD \\
\cline { 2 - 5 } & \multicolumn{5}{c}{$(\mathrm{g} / 100 \mathrm{~g})$} & \\
C16:0 & 11.1 & 10.8 & 10.6 & 11.0 \\
C18:0 & 3.85 & 4.36 & 4.43 & 4.16 \\
C18:1 $(n-9)$ & 20.2 & 21.8 & 21.7 & 22.2 \\
C18:2 $(n-6)$ & 54.7 & 52.2 & 52.5 & 51.1 \\
C18:3 $(n-3)$ & 6.21 & 4.65 & 4.75 & 4.13 \\
C22:0 & 0.45 & 0.33 & 0.32 & 0.36 \\
Other & 3.45 & 5.86 & 5.73 & 7.07 \\
\hline
\end{tabular}

${ }^{1} \mathrm{SBO}=$ soybean oil, MIX = calcium salt and fatty acyl amide $(80: 20$, $\mathrm{wt} / \mathrm{wt}$ ) of SBO, CAS = calcium salt of SBO, and AMD = fatty acyl amide of SBO.

genation also was tested for a mixture (20:80) of amide and calcium salts. Amides of SBO were added at the time of calcium salt formation to determine whether the calcium salts might shield the amide bond from microbial attack, thus enhancing protection of fatty amides from biohydrogenation.

\section{MATERIALS AND METHODS}

\section{Fat Supplements}

Fatty acid composition of the fat supplements is shown in Table 1. Commercial SBO (North Arkansas Wholesale Co. Inc., Bentonville, AR) used for the SBO diet contained $55 \%$ linoleic acid, $20 \%$ oleic acid, and $11 \%$ palmitic acid as determined by GLC. The fatty acyl amide, calcium salt, and a mixture of the calcium salt and fatty acyl amide (80:20, wt/wt) of SBO were supplied by Church and Dwight Co., Inc. (Princeton, NJ). The amide and calcium salt mixture was made by adding amides of SBO to the reactor at the terminal stage of calcium salt formation, at a point where both fat sources were plastic and could associate. The decision to include $20 \%$ amide in the amide and calcium salt mix was arbitrary, but was based on having a larger mass of calcium salts to surround and protect the fatty amide. All fat supplements were added to the concentrate ingredients without further processing.

\section{Cows and Diets}

Four multiparious Holstein cows (103 \pm 19 DIM) fitted with ruminal cannulas were used in a $4 \times 4$ Latin square design. Trial periods consisted of $21 \mathrm{~d}$ with sample collection on the last $4 \mathrm{~d}$ of each period. Cows were housed in a tie-stall barn and had free access to water and assigned diets. Feed was offered each day at 0800 and $1600 \mathrm{~h}$. Refusals were removed and recorded daily at $0700 \mathrm{~h}$. Diets were fed to allow 5\% orts. Cows were milked daily at 0700 and $1900 \mathrm{~h}$. Ten grams of chromic oxide in gelatin capsules were dosed twice daily (over the last $10 \mathrm{~d}$ of each period) via ruminal cannula just prior to feeding as an indigestible feed marker.

Diets were fed as a TMR consisting of forage and concentrate (1:1; DM basis). The forage portion contained corn silage and alfalfa hay in a 9:1 ratio (DM basis). Diets consisted of TMR plus 1) SBO added at $2.45 \%$ of DM, 2) calcium salt of SBO added at $2.75 \%$ of DM (CAS), 3) amide of SBO added at $2.75 \%$ of DM (AMD), and 4) a mixture of the calcium salt and amide (80:20, wt/wt) of SBO added at $2.75 \%$ of DM (MIX). Urea was added to SBO to balance the small amount of $\mathrm{N}$ supplied by the amide. Urea was left out of the MIX and CAS diets to determine any possible advantage of the amide over CAS, regardless of whether that advantage was caused by the $\mathrm{N}$ or fatty acid moieties. Fat sources were added to the TMR at concentrations needed to equalize added linoleic acid across all treatments. Ingredients, chemical composition, and fatty acid concentrations of the TMR are shown in Table 2.

\section{Sampling and Analysis}

Corn silage was analyzed weekly for DM, and adjustments were made to the ration to maintain a 50:50 (DM basis) forage:concentrate ratio. Forage (corn silage + alfalfa hay), concentrate, and ort samples were taken weekly, composited by cow and by period, dried at $55^{\circ} \mathrm{C}$, and then ground in a Wiley Mill (Arthur H. Thomas Co., Philadelphia, PA) through a 2-mm sieve. Ground samples were analyzed for DM $\left(100^{\circ} \mathrm{C}\right)$, Kjeldahl $\mathrm{N}$ (AOAC, 1990), NDF (Van Soest et al., 1991), and fatty acids. Fatty acids were converted to methyl esters by incubation in $5 \%$ methanolic $\mathrm{HCl}$ for $16 \mathrm{~h}$ at $70^{\circ} \mathrm{C}$ as described by Jenkins et al. (2001). One milliliter of heptadecanoic acid (Cat. No. N-17-A ; Nu-Check-Prep, Inc., Elysian, MN) was added as an internal standard ( $2 \mathrm{mg} /$ $\mathrm{mL}$ ). Fatty acid methyl esters were analyzed via GLC on a Shimadzu GC-14A equipped with a $100-\mathrm{m} \times 0.25$ $\mathrm{mm}$ i.d. WCOT-fused silica column coated $(0.20-\mu \mathrm{m}$ film thickness) with CP-Sil 88 (Cat. No. 7489; Chrompack, Inc., Raritan, NJ). Initial oven temperature was $70^{\circ} \mathrm{C}$ (4 min), which was raised $13^{\circ} \mathrm{C} / \mathrm{min}$ to $175^{\circ} \mathrm{C}$ (held for $27 \mathrm{~min}$ ) and then increased again at $4^{\circ} \mathrm{C} / \mathrm{min}$ to a final temperature of $215^{\circ} \mathrm{C}$ (held for $11 \mathrm{~min}$ ). Temperatures of the injector and detector were $250^{\circ} \mathrm{C}$. Hydrogen was used as the carrier gas at a linear velocity of $40 \mathrm{~cm} / \mathrm{s}$. Nutrient composition of the diets (Table 2) was calculated based on forage and grain analyses and their contribution to the diet.

Omasal samples were taken at 0800, 1100, and 1400 $\mathrm{h}$ on $\mathrm{d} 19$ of each period. Sample times were delayed 1 $\mathrm{h}$ on $\mathrm{d} 20$ and $2 \mathrm{~h}$ on $\mathrm{d} 21$, yielding a sample taken 
Table 2. Ingredients and composition of the TMR fed to Holstein cows.

\begin{tabular}{|c|c|c|c|c|}
\hline & \multicolumn{4}{|c|}{ Diet $^{1}$} \\
\hline & SBO & MIX & CAS & AMD \\
\hline \multicolumn{5}{|l|}{ Ingredient (\% of DM) } \\
\hline Corn silage & 45.0 & 45.0 & 45.0 & 45.0 \\
\hline Alfalfa hay & 5.00 & 5.00 & 5.00 & 5.00 \\
\hline Cracked corn & 16.9 & 16.9 & 16.9 & 16.9 \\
\hline Whole barley & 11.7 & 11.7 & 11.7 & 11.7 \\
\hline Soybean meal & 15.6 & 15.6 & 15.6 & 15.6 \\
\hline Soybean oil & 2.45 & & & \\
\hline Ca salt/amide (80:20) of soybean oil & & 2.75 & & \\
\hline Ca salts of soybean oil & & & 2.75 & \\
\hline Amide of soybean oil & & & & 2.75 \\
\hline Defluorinated phosphate & 1.10 & 1.10 & 1.10 & 1.10 \\
\hline Limestone & 0.55 & 0.55 & 0.55 & 0.55 \\
\hline Sodium bicarbonate & 0.65 & 0.65 & 0.65 & 0.65 \\
\hline Trace mineral salt ${ }^{2}$ & 0.50 & 0.50 & 0.50 & 0.50 \\
\hline $\mathrm{K}, \mathrm{Mg}, \mathrm{S}^{3}$ & 0.27 & 0.27 & 0.27 & 0.27 \\
\hline Urea & 0.27 & 0.00 & 0.00 & 0.00 \\
\hline Zn methionine ${ }^{4}$ & 0.07 & 0.07 & 0.07 & 0.07 \\
\hline Vitamin A, D, \& E premix ${ }^{5}$ & 0.025 & 0.025 & 0.025 & 0.025 \\
\hline $\mathrm{CP}$ & 174 & 169 & 167 & 176 \\
\hline $\mathrm{NDF}$ & 261 & 263 & 260 & 266 \\
\hline Fatty acids & 52.2 & 53.6 & 57.1 & 61.1 \\
\hline C12:0 & 0.20 & 0.20 & 0.19 & 0.20 \\
\hline C14:0 & 0.06 & 0.07 & 0.09 & 0.07 \\
\hline C16:0 & 7.55 & 7.55 & 8.19 & 8.49 \\
\hline C18:0 & 1.65 & 1.79 & 2.09 & 2.05 \\
\hline C18:1(n-9) & 9.83 & 10.3 & 11.3 & 12.1 \\
\hline $\mathrm{C} 18: 2(n-6)$ & 25.0 & 25.6 & 26.0 & 29.4 \\
\hline $\mathrm{C} 18: 3(n-3)$ & 3.30 & 3.09 & 3.10 & 3.29 \\
\hline C20:0 & 0.25 & 0.22 & 0.24 & 0.24 \\
\hline Other & 4.36 & 4.78 & 5.90 & 5.26 \\
\hline
\end{tabular}

${ }^{1}$ Diets contained either $2.45 \%$ soybean oil (SBO), $2.75 \%$ calcium salts of SBO (CAS), $2.75 \%$ amides of SBO (AMD), or $2.75 \%$ blended fat (MIX) consisting of calcium salts and amides of SBO (80:20, wt/wt).

${ }^{2}$ Morten Salt Division (Chicago, IL) specified to contain: 93 to $98 \% \mathrm{NaCl}$, not less than $0.35 \% \mathrm{Zn}, 0.28 \%$ $\mathrm{Mn}, 0.175 \% \mathrm{Fe}, 0.035 \% \mathrm{Cu}, 0.007 \% \mathrm{I}$, and $0.007 \% \mathrm{Co}$.

${ }^{3}$ Dynamate (Eastern Minerals Inc., Henderson, NC) contained not less than $18 \% \mathrm{~K}, 11 \% \mathrm{Mg}$, and $22 \%$ S.

${ }^{4}$ Zinpro Corporation (Chaska, MN).

${ }^{5}$ Lutavit (BASF Co., Mt. Olive, NJ) supplied 22,000 IU/g of vitamin $\mathrm{D}_{3}, 17,600 \mathrm{IU} / \mathrm{g}$ of vitamin A, and 66 $\mathrm{IU} / \mathrm{g}$ of vitamin $\mathrm{E}$.

at each hour between feedings. Omasal samples were taken using a modified procedure of Huhtanen et al. (1997). Briefly, omasal samples were aspirated through tygon tubing ( $16 \mathrm{~mm}$ i.d.) that was passed through the ruminal cannula and inserted into the reticulo-omasal opening. A hand-operated vacuum pump (36 cc per stroke) was attached to a filter flask, and $150 \mathrm{~mL}$ of omasal contents were retrieved. Omasal samples were composited over sampling times and immediately frozen. Frozen samples were later thawed and a subsample was lyophilized. Lyophilized samples were ground in a centrifugal mill through a $0.5-\mathrm{mm}$ sieve and analyzed for DM $\left(100^{\circ} \mathrm{C}\right)$, Kjeldahl N (AOAC, 1990), NDF (Van Soest et al., 1991), Cr (atomic absorption, Brookside Labs, Inc., New Knoxville, $\mathrm{OH}$ ), and fatty acid content as previously described. To separate individual trans-C18:1 isomers in omasal contents, the omasal samples were re-analyzed on the previously mentioned GLC according to Griinari et al. (1998) with minor modifications to the column temperature. Initial column temperature was $160^{\circ} \mathrm{C}$ for 45 min then ramped $4^{\circ} \mathrm{C} /$ min to a final temperature of $215^{\circ} \mathrm{C}$ (held for $11 \mathrm{~min}$ ). Chromatograms of the milk fatty acids were similar to the chromatographs reported by Griinari et al. (1998), which provided a basis for peak identification. Further verification of peak identity was established by comparison of peak retention times to commercially purchased trans monoene standards (Supelco, Bellefonte, PA).

Daily milk production was recorded electronically throughout the duration of the experiment. Three consecutive morning and evening milk samples ( 6 samples) were taken at the end of each period. The samples were composited by cow, and a subsample containing isobronopol was sent to DHIA (Virginia Dairy Herd Improve- 
Table 3. Intake, omasal flow, and apparent ruminal digestibilities of DM and fiber in Holstein cows fed diets containing protected and unprotected soybean oil (SBO).

\begin{tabular}{|c|c|c|c|c|c|c|c|c|}
\hline & \multicolumn{4}{|c|}{$\operatorname{Diet}^{1}$} & \multirow[b]{2}{*}{ SEM } & \multicolumn{3}{|c|}{ Contrast $^{2}$} \\
\hline & SBO & MIX & CAS & AMD & & 1 & 2 & 3 \\
\hline \multicolumn{9}{|c|}{ Intake $(\mathrm{kg} / \mathrm{d})$} \\
\hline DM & 20.1 & 20.1 & 20.0 & 17.2 & 0.61 & NS & 0.08 & 0.02 \\
\hline $\mathrm{NDF}$ & 5.25 & 5.30 & 5.21 & 4.57 & 0.16 & NS & 0.08 & 0.03 \\
\hline \multicolumn{9}{|c|}{ Flow to omasum $(\mathrm{kg} / \mathrm{d})$} \\
\hline DM & 12.4 & 12.5 & 13.9 & 10.7 & 0.93 & NS & NS & 0.05 \\
\hline $\mathrm{NDF}$ & 2.56 & 2.63 & 3.18 & 2.34 & 0.19 & NS & NS & 0.02 \\
\hline \multicolumn{9}{|c|}{ Rumen digestibility (\%) } \\
\hline DM & 35.9 & 39.6 & 28.7 & 35.5 & 4.71 & NS & NS & $\mathrm{NS}$ \\
\hline NDF & 49.2 & 51.2 & 36.9 & 46.0 & 4.19 & NS & NS & NS \\
\hline
\end{tabular}

${ }^{1}$ Diets contained either $2.45 \%$ SBO, $2.75 \%$ calcium salts of SBO (CAS), $2.75 \%$ amides of SBO (AMD), or $2.75 \%$ blended fat (MIX) consisting of calcium salts and amides of SBO (80:20, wt/wt).

${ }^{2}$ Contrasts are designed as 1) SBO vs. other diets, 2) MIX vs. CAS and AMD, and 3) CAS vs. AMD.

ment Association, Blacksburg) for analysis of protein and SCC using near infrared analysis (AOAC, 1990). A separate sample from the composite (without isobronopol) was stored at $-4^{\circ} \mathrm{C}$. Samples without isobronopol were allowed to equilibrate to room temperature and were divided into two subsamples. The first of the subsamples were centrifuged at $21,000 \times g$ for $30 \mathrm{~min}$ at $4^{\circ} \mathrm{C}$ to separate the milk fat for fatty acid analysis. Fatty acids in milk fat were converted to methyl esters in sodoium methoxide followed by methanolic $\mathrm{HCl}$ as described by Kramer et al. (1997). Fatty acid content was determined via GLC using the program previously described. The second subsample was analyzed for fat content using the Roese-Gottlieb method (AOAC, 1990).

\section{Data Presentation and Statistical Analysis}

Although complete fatty acid profiles were obtained for omasal samples, only C18 fatty acids are presented to maintain focus on the main study objective, i.e., the ability of the fat supplements to resist ruminal biohydrogenation. The fatty acid designations of C18:0, C18:1 $(n-9), \mathrm{C} 18: 2(n-6)$, and C18:3 (n-3) refer to stearic, oleic, linoleic, and linolenic acids, respectively. All data were analyzed as a $4 \times 4$ Latin square using the general linear model procedure of SAS (2000). The model included effects caused by diet, animal, and period. Planned comparisons of treatments included three orthogonal contrasts 1) SBO vs. other fat supplements, 2) MIX vs. AMD and CAS, and 3) AMD vs. CAS. Exact $P \leq 0.10$ are shown for each contrast.

\section{RESULTS AND DISCUSSION}

\section{Intake and Ruminal Digestibilities}

Dry matter $(P=0.02)$ and NDF intakes $(P=0.03)$ were lower for AMD than they were for CAS (Table 3). A previous study (Jenkins, 1999) reported a linear decline in DMI as oleamide increased in the diet of cows, where DMI was depressed $1.7 \mathrm{~kg} / \mathrm{d}$ for each percentage unit increase in dietary oleamide. When the fatty acyl amide was included in the MIX $(0.55 \%$ of ration DM), DMI was not suppressed compared with CAS. Sheep responded differently to diets containing unsaturated amides. Dry mater intake did not change when sheep were fed 5\% linoleamide compared with sheep fed a control diet (Jenkins and Adams, 2002). Because of the lower DMI for AMD in this study, flows of DM and NDF to the omasum were reduced $(P \leq$ 0.05) for AMD compared with CAS (Table 3), although ruminal DM digestibilities were similar.

Flows of DM and NDF to the omasal canal were estimated in this study from a twice-daily pulse dose of a single marker $(\mathrm{Cr})$. It has been suggested that a triple marker system is necessary to obtain accurate flow measurements from the omasal canal because of unrepresentative sampling of digesta particulate matter entering that site (Ahvenjarvi et al., 2000). In a later study (Ahvenjarvi et al., 2003), single markers (Yb, Cr, Co, or indigestible NDF) were shown to concentrate in different digesta fractions (liquid, small particulate, or large particulate phases) and resulted in large differences in flow measurements to the omasal canal. Despite $\mathrm{Cr}$ associating more with the large particulate fraction, there was good agreement between $\mathrm{Cr}$ alone and a triple marker $(\mathrm{Co}+\mathrm{Yb}+\mathrm{Cr})$ system for determining flows of organic matter $(r=0.88)$ or $\mathrm{NDF}(\mathrm{r}=0.98)$ to the omasal canal (Ahvenjarvi et al., 2003).

Omasal sampling using $\mathrm{Cr}$ in this study yielded digestibilities of DM and fiber that were similar to digestibilities reported in previous investigations. For instance, ruminal digestibilities of DM and NDF averaged 37.7 and $44.9 \%$, respectively, in a study using omasal sampling with three markers (Reynal and Broderick, 2003) compared with ruminal digestibilities of DM and NDF that averaged 34.9 and $45.8 \%$, respectively, in 
Table 4. Intake and omasal flow of total and C18 fatty acids and biohydrogenation of C18 fatty acids in Holstein cows fed diets containing protected and unprotected soybean oil (SBO).

\begin{tabular}{|c|c|c|c|c|c|c|c|c|}
\hline & \multicolumn{4}{|c|}{$\operatorname{Diet}^{1}$} & \multirow[b]{2}{*}{ SEM } & \multicolumn{3}{|c|}{ Contrast $^{2}$} \\
\hline & SBO & MIX & CAS & $\mathrm{AMD}$ & & 1 & 2 & 3 \\
\hline \multicolumn{9}{|l|}{ Intake, $g / d$} \\
\hline Total FA & 1052.1 & 1090.1 & 1111.8 & 1047.6 & 50.5 & NS & NS & NS \\
\hline C18:0 & 33.2 & 36.1 & 41.8 & 35.2 & 1.1 & NS & NS & 0.01 \\
\hline C18:1 (n-9) & 197.7 & 207.5 & 226.8 & 208.0 & 6.0 & 0.06 & NS & 0.07 \\
\hline $\mathrm{C} 18: 2(n-6)$ & 502.3 & 516.4 & 520.5 & 506.0 & 14.4 & NS & NS & NS \\
\hline C18:3 (n-3) & 66.0 & 62.3 & 61.8 & 56.4 & 2.0 & 0.04 & NS & 0.10 \\
\hline Total C18 ${ }^{3}$ & 799.2 & 822.2 & 850.8 & 805.6 & 23.3 & NS & NS & NS \\
\hline \multicolumn{9}{|c|}{ Flow to omasum, g/d } \\
\hline Total FA & 1108.3 & 1170.1 & 1136.0 & 1050.9 & 115.4 & $\mathrm{NS}$ & NS & NS \\
\hline C18:0 & 519.9 & 433.3 & 490.2 & 410.8 & 39.6 & NS & NS & NS \\
\hline trans C18:1 & 156.7 & 229.8 & 140.3 & 198.7 & 40.0 & NS & NS & NS \\
\hline C18:1 (n-9) & 36.1 & 41.3 & 48.5 & 85.5 & 9.5 & 0.09 & 0.07 & 0.03 \\
\hline C18:2 (n-6) & 24.7 & 32.7 & 39.1 & 39.2 & 5.1 & 0.08 & NS & NS \\
\hline C18:3 (n-3) & 5.2 & 6.1 & 6.9 & 5.5 & 0.7 & NS & NS & NS \\
\hline Total C18 ${ }^{4}$ & 742.5 & 743.2 & 725.0 & 739.7 & 81.2 & NS & NS & NS \\
\hline \multicolumn{9}{|c|}{ Omasal concentration, $\mathrm{g} / \mathrm{kg}$ of $\mathrm{DM}$} \\
\hline C18:0 & 42.0 & 35.9 & 35.4 & 38.5 & 2.76 & NS & NS & NS \\
\hline trans C18:1 & 12.6 & 16.9 & 10.3 & 18.5 & 2.44 & NS & NS & 0.05 \\
\hline C18:1 (n-9) & 2.87 & 3.23 & 3.56 & 7.98 & 0.96 & NS & 0.08 & 0.02 \\
\hline C18:2 (n-6) & 1.95 & 2.51 & 2.83 & 3.67 & 0.40 & 0.07 & NS & NS \\
\hline $\mathrm{C} 18: 3(n-3)$ & 0.42 & 0.46 & 0.50 & 0.52 & 0.04 & NS & NS & NS \\
\hline \multicolumn{9}{|c|}{ Biohydrogenation, \% } \\
\hline C18:1 $(n-9)^{5}$ & 81.1 & 80.7 & 77.9 & 61.4 & 4.71 & NS & NS & 0.05 \\
\hline C18:1 $(n-9)^{6}$ & 80.6 & 77.9 & 74.4 & 55.4 & 4.68 & 0.08 & 0.06 & 0.03 \\
\hline C18:1 $(n-9)^{7}$ & 70.3 & 68.1 & 67.9 & 33.0 & 8.10 & NS & NS & 0.02 \\
\hline $\mathrm{C} 18: 2(n-6)^{5}$ & 94.8 & 93.9 & 92.2 & 92.4 & 1.05 & NS & NS & NS \\
\hline $\mathrm{C} 18: 2(n-6)^{6}$ & 94.8 & 93.2 & 91.1 & 91.7 & 0.68 & 0.01 & 0.08 & NS \\
\hline $\mathrm{C} 18: 2(n-6)^{7}$ & 92.2 & 90.2 & 89.1 & 87.5 & 1.40 & 0.10 & NS & NS \\
\hline
\end{tabular}

${ }^{1}$ Diets contained either $2.45 \%$ SBO, $2.75 \%$ calcium salts of SBO (CAS), $2.75 \%$ amides of SBO (AMD), or $2.75 \%$ blended fat (MIX) consisting of calcium salts and amides of SBO (80:20, wt/wt).

${ }^{2}$ Contrasts are designed as 1) SBO vs. other diets, 2) MIX vs. CAS and AMD, and 3) CAS vs. AMD.

${ }^{3}$ Consisting of C18:0, C18:1 (n-9), C18:2 (n-6), and C18:3 (n-3).

${ }^{4}$ Consisting of C18:0, trans C18:1, C18:1 ( $\left.n-9\right), \mathrm{C} 18: 2(n-6)$, and C18:3 ( $\left.n-3\right)$.

${ }^{5}$ Percentage biohydrogenation based on total grams of fatty acid loss across the rumen divided by the fatty acid intake.

${ }^{6}$ Percentage biohydrogenation as determined by Wu et al. (1991).

${ }^{7}$ Percentage biohydrogenation based on the concentration of fatty acid in feed minus omasum divided by feed.

the present study. Hristov and Ropp ( 2003) reported ruminal digestibilities of $\mathrm{DM}$ and NDF that averaged 36.3 and $38.9 \%$, respectively, when calculated from duodenal samples.

\section{Ruminal Biohydrogenation of Unsaturated Fatty Acids}

Total fatty acid intakes were similar for all diets despite the lower DMI for AMD (Table 4). This can be attributed to the higher fatty acid concentration in the AMD diet (Table 2). The actual fatty acid concentration in the amide fat supplement was higher than expected, which led to overestimating the amount needed in the ration for balancing fatty acid intakes. Flows of fatty acid to the omasum were not affected by diet. Therefore, recoveries of total fatty acids at the omasum were the same for all diets and averaged $103.8 \%$. Fatty acid loss across the rumen is expected to be small or negligible based on studies showing minor microbial metabolism of long-chain fatty acids and insignificant absorption across the ruminal epithelium (Doreau and Chilliard, 1997). Fatty acids reaching the duodenum may exceed fatty acid intake because of contributions from microbial de novo synthesis of long-chain fatty acids (Doreau and Chilliard, 1997). However, in many previous studies, fatty acid loss across the rumen was observed. Doreau and Chilliard (1997) examined 113 observations from the literature on fatty acid balance across the rumen with an overall average of $80.1 \%$ recovery of ingested fatty acids at the duodenum.

Total C18 intakes were similar for all diets (Table 4). Also, intakes of C18:2 (n-6) were equal across treatments, which was predetermined by the selection of fat 
levels added to the TMR. Intake of C18:2 (n-6) for AMD was similar to the other diets because its lower DMI was offset by a higher C18:2 (n-6) concentration (Table 2 ). Intakes of all remaining fatty acids were lower for AMD than for CAS.

The flow of C18:1 (n-9) to the omasum was lower $(P=0.09)$ for SBO than it was for the protected fat supplements. The AMD delivered $37 \mathrm{~g}$ more C18:1(n9) to the omasum than CAS, even though C18:1(n-9) intake was lower for AMD (208 vs. $227 \mathrm{~g} / \mathrm{d}$ ). The flow of C18:2 $(n-6)$ also was lower $(P=0.08)$ for SBO than it was for the other treatments, demonstrating some efficacy for the protected fat supplements to deliver unsaturated fatty acids post ruminally. Omasal flow of C18:2 (n-6) did not differ among the AMD, CAS, or MIX diets. Expressing omasal fatty acids in grams per kilogram of DM had similar diet effects as seen for flow $(\mathrm{g} / \mathrm{d})$. The only difference was that C18:1 (n-9) for SBO did not differ from the protected fats when expressed on a concentration basis.

Ruminal biohydrogenation in this study was calculated and compared using 3 different methods. The first measure of biohydrogenation was calculated based on the total grams of fatty acid loss across the rumen (consumed - omasal flow) as a percentage of fatty acid consumed. When examined this way, C18:2 (n-6) biohydrogenation ranged from 92 to $95 \%$ and did not differ among diets. Unlike C18:2 (n-6), the AMD diet had lower $(P=0.05)$ biohydrogenation of C18:1(n-9) compared with CAS $(61.4 \%$ vs. $77.9 \%)$.

The extensive biohydrogenation of C18:2 (n-6) observed in this study is consistent with previous results where the majority of unsaturated fatty acids consumed by ruminants were lost prior to the duodenum. Losses of C18:2 (n-6) and C18:3 (n-3) from the mouth to duodenum in ruminant species averaged 80 and $92 \%$, respectively, in a data set containing more than 100 observations from published studies (Doreau and Chilliard, 1997).

The second measure of biohydrogenation was calculated using the method described by Wu et al. (1991). This method corrects for losses in C18 flow to the omasum by calculating the ratio of individual 18-carbon fatty acids and total 18-carbon fatty acids ingested relative to the amount of individual 18-carbon fatty acids and total 18-carbon fatty acids reaching the omasum, respectively. Using this approach, C18:2 (n-6) biohydrogenation was higher $(P=0.01)$ for SBO than it was for the other fat supplements, and MIX was higher $(P=$ $0.08)$ than CAS or AMD. For C18:1 (n-9) biohydrogenation, the SBO diet had higher biohydrogenation than the protected fats, and the AMD diet had lower $(P=$ $0.03)$ biohydrogenation than CAS (55.4\% vs. $74.4 \%)$.
The third measure of biohydrogenation was calculated based on the differences between fatty acid concentrations in the feed and omasal contents divided by their feed concentration. When examined this way, the only diet effects were higher $(P=0.10)$ ruminal biohydrogenation of C18:2 (n-6) for SBO than for the protected fats and lower $(P=0.02)$ biohydrogenation of C18:1(n-9) for AMD than for CAS. Determining ruminal biohydrogenation on a concentration basis avoids the need to use digestibility markers to determine digesta flow.

There were several common diet effects on biohydrogenation across all calculation methods. First, biohydrogenation of C18:1 (n-9) was less for AMD than for CAS, but AMD had no advantage over CAS for reducing biohydrogenation of C18:2 (n-6). The amide bond was proposed to reduce fatty acid loss in ruminal contents by tying up the carboxyl group, which must be unbound to promote the initial step in biohydrogenation (Doreau and Chilliard, 1997). This study suggests that the amide bond in simple fatty amides (made by reacting the carboxyl group with ammonia) is less stable when the fatty acyl chain is polyunsaturated vs. monounsaturated. Perhaps structural differences in the fatty acyl chain alter steric hindrances around the amide bond, affecting their stability to enzymatic attack.

A second common dietary effect on biohydrogenation across all 3 methods of calculation was that the MIX had little effect on biohydrogenation. The MIX attempted to use calcium salts as an encapsulating agent to enhance protection of amides by shielding the amide bond from microbial attack. If this were successful, biohydrogenation of unsaturated fatty acids in MIX would be lower than unsaturated fatty acids in AMD. There was no evidence of any advantage for MIX. Biohydrogenation was the same or higher for MIX than it was for CAS or AMD. It is possible that fatty acid profile of calcium salts may affect encapsulation properties. Calcium salts of saturated fatty acids are less dissociated than calcium salts of unsaturated fatty acids at any given ruminal pH (Sukhija and Palmquist, 1990). Because the calcium salts in this study were mostly unsaturated, the physical barrier surrounding the amide fatty acids might have been weakened by dissociation.

Calcium salts are rumen-inert and minimize disruption of fermentation, but they should undergo limited biohydrogenation if a free carboxyl group is required for hydrogenation as previously reported (Doreau and Chilliard, 1997). Fotouhi and Jenkins (1992) offered an explanation for biohydrogenation of calcium salts. They stated that, at normal ruminal $\mathrm{pH}$, calcium linoleate is in equilibrium with a small amount of its corresponding free acid, i.e., linoleic acid. The linoleic acid fraction undergoes biohydrogenation because of its free carboxyl 
Table 5. Concentration of individual and total C18:1 trans isomers in omasal contents of Holstein cows fed diets containing protected and unprotected soybean oil (SBO).

\begin{tabular}{|c|c|c|c|c|c|c|c|c|}
\hline & \multicolumn{4}{|c|}{ Diet $^{1}$} & \multirow[b]{2}{*}{ SEM } & \multicolumn{3}{|c|}{ Contrast $^{2}$} \\
\hline & SBO & MIX & CAS & AMD & & 1 & 2 & 3 \\
\hline & \multicolumn{8}{|c|}{$\longrightarrow(\mathrm{g} / \mathrm{kg}$ of $\mathrm{DM}) \longrightarrow$} \\
\hline trans $6-8$ & 0.76 & 1.03 & 0.77 & 0.84 & 0.13 & NS & NS & NS \\
\hline trans 9 & 0.46 & 0.53 & 0.45 & 0.35 & 0.08 & NS & NS & NS \\
\hline trans 10 & 1.41 & 3.05 & 1.40 & 9.89 & 1.98 & NS & NS & 0.02 \\
\hline trans 11 & 8.80 & 10.6 & 6.43 & 6.16 & 0.94 & NS & 0.01 & NS \\
\hline trans 12 & 1.22 & 1.66 & 1.24 & 1.31 & 0.16 & NS & 0.10 & NS \\
\hline Total trans & 12.6 & 16.9 & 10.3 & 18.5 & 2.44 & NS & NS & 0.05 \\
\hline
\end{tabular}

${ }^{1}$ Diets contained either $2.45 \%$ SBO, $2.75 \%$ calcium salts of SBO (CAS), $2.75 \%$ amides of SBO (AMD), or $2.75 \%$ blended fat (MIX) consisting of calcium salts and amides of SBO (80:20, wt/wt).

${ }^{2}$ Contrasts are designed as 1) SBO vs. other diets, 2) MIX vs. CAS and AMD, and 3) CAS vs. AMD.

group, forcing continual dissociation of calcium linoleate to maintain the linoleic acid-calcium linoleate equilibrium. Major end products from linoleic acid biohydrogenation, such as stearic acid, are then converted to the calcium salt to maintain the proper stearic acidcalcium stearate equilibrium. The end result is that most of the fatty acids remain as calcium salts and maintain ruminal inertness, but are converted from unsaturated to saturated.

\section{Trans Fatty Acids in Omasal and Milk Samples}

Total trans $\mathrm{C} 18: 1$ concentrations ( $\mathrm{g} / \mathrm{kg}$ of $\mathrm{DM})$ in the omasum were higher $(P=0.05)$ for AMD than they were for CAS (Table 5). Most the higher trans C18:1 concentration for AMD was due to a higher $(P=0.02)$ concentration of the trans-10 isomer. The MIX had higher concentrations of trans-11 $(P=0.01)$ and trans12 C18:1 $(P=0.10)$ compared with the other protected fat supplements.

A marked increase in trans $\mathrm{C} 18: 1$ in ruminal contents or milk was not seen in previous studies where fatty amides were fed to dairy cows at substantially higher concentrations than the $2.75 \%$ amide fed in this study. For instance, total trans C18:1 concentration was not elevated in ruminal contents of Holstein cows fed $4.2 \%$ oleamide (Jenkins et al., 2000). Conversely, Jenkins and Adams (2002) reported increased concentration of trans C18:1 in duodenal contents of sheep fed 5\% linoleamide. Perhaps the amide-induced increase in ruminal trans C18:1 concentration may depend on the degree of amide unsaturation. In the present cow study and the previous sheep study (Jenkins and Adams, 2002), the amide supplement contained linoleic acid as the predominant fatty acid and also elevated ruminal trans $\mathrm{C} 18: 1$ concentrations.

High concentrations of polyunsaturated fatty acids in ruminal contents can cause accumulation of trans C18:1 by inhibiting the conversion of trans C18:1 to stearic acid, especially when they are present as the free acid (Harfoot and Hazlewood, 1988). Extensive cleavage of the amide bond by the ruminal microorganisms would release linoleic acid and perhaps inhibit the conversion of trans C18:1 to stearic acid. However, the release of linoleic acid from SBO should equal linoleic acid release from AMD, given that triacylglycerols undergo extensive lipolysis in the rumen (Harfoot and Hazlewood, 1988).

An alternative explanation is direct inhibition of biohydrogenation by intact amides. Kepler et al. (1970) demonstrated inhibition of linoleate isomerase by linoleamide and other derivatives of the carboxyl group. Inhibition of linoleate isomerase would cause accumulation of linoleic acid but not trans C18:1, unless the amide also inhibited reductases that convert trans C18:1 to stearic acid. Accounting for the trans-10 C18:1 accumulation is difficult, unless the amides of SBO redirected linoleic acid biohydrogenation from the cis-9, trans-11 C18:2 and trans-11 C18:1 pathway to a trans10, cis-12 C18:2 and trans-10 C18:1 pathway (Griinari and Bauman, 1999).

Consistent with trans $\mathrm{C} 18: 1$ changes in omasal contents, trans $\mathrm{C} 18: 1$ in milk also was higher $(P=0.08)$ for AMD than it was for CAS (Table 6). When analyzed for milk fat percentage by the Roese-Gottlieb procedure (AOAC, 1990), SBO had a higher $(P=0.08)$ percentage of milk fat. Milk fat percentage was lower $(P=0.05)$ for AMD than it was for CAS. The lower milk fat percentage for diets containing amide is believed to be due to the high concentration of trans-10 18:1 found in the omasum and milk. Baumgard et al. (2000) reported severe milk fat depression when CLA isomers containing a trans-10 double bond were infused abomasally. Griinari et al. (1998) specifically associated milk fat depression reported in their study to trans-octadecenoic acids produced by incomplete biohydrogenation.

In milk, C18:1 $(n-9)$ was higher $(P<0.01)$ for AMD than for CAS, consistent with the lower biohydrogena- 
Table 6. Yield, composition, and fatty acid profile of milk from Holstein cows fed diets containing protected and unprotected soybean oil (SBO).

\begin{tabular}{|c|c|c|c|c|c|c|c|c|}
\hline & \multicolumn{4}{|c|}{$\operatorname{Diet}^{1}$} & \multirow[b]{2}{*}{ SEM } & \multicolumn{3}{|c|}{ Contrast $^{2}$} \\
\hline & SBO & MIX & CAS & AMD & & 1 & 2 & 3 \\
\hline \multicolumn{9}{|c|}{ Milk yield and composition } \\
\hline Yield, kg/d & 34.6 & 32.5 & 32.0 & 32.4 & 0.99 & 0.09 & NS & NS \\
\hline Protein, \% & 2.82 & 2.84 & 2.77 & 2.81 & 0.05 & NS & NS & NS \\
\hline Fat, $\%$ & 3.11 & 2.56 & 3.04 & 2.46 & 0.18 & 0.08 & NS & 0.05 \\
\hline \multicolumn{9}{|c|}{ Fatty acids, g/100 g } \\
\hline $\mathrm{C} 4: 0$ & 2.45 & 2.19 & 2.28 & 1.84 & 0.10 & 0.02 & NS & 0.02 \\
\hline $\mathrm{C} 6: 0$ & 1.91 & 1.57 & 1.86 & 1.15 & 0.07 & $<0.01$ & NS & $<0.01$ \\
\hline $\mathrm{C} 8: 0$ & 1.06 & 0.83 & 1.10 & 0.58 & 0.06 & 0.01 & NS & $<0.01$ \\
\hline C10:0 & 2.27 & 1.83 & 2.53 & 1.30 & 0.15 & 0.07 & NS & $<0.01$ \\
\hline C11:0 & 0.20 & 0.17 & 0.21 & 0.09 & 0.02 & 0.06 & NS & $<0.01$ \\
\hline C12:0 & 2.61 & 2.32 & 2.99 & 1.81 & 0.16 & NS & NS & $<0.01$ \\
\hline C14:0 & 9.39 & 9.19 & 10.4 & 7.49 & 0.52 & NS & NS & 0.01 \\
\hline C14:1 & 0.73 & 0.91 & 0.74 & 0.75 & 0.10 & NS & NS & NS \\
\hline C15:0 & 0.80 & 0.80 & 0.86 & 0.76 & 0.02 & NS & NS & 0.03 \\
\hline C16:0 & 23.8 & 23.6 & 25.1 & 22.3 & 0.66 & NS & NS & 0.03 \\
\hline $\mathrm{C} 16: 1$ & 1.36 & 1.64 & 1.37 & 1.65 & 0.10 & NS & NS & 0.10 \\
\hline C18:0 & 13.8 & 12.0 & 12.0 & 12.9 & 0.50 & 0.04 & NS & NS \\
\hline trans $\mathrm{C} 18: 1$ & 5.60 & 7.64 & 6.03 & 9.95 & 1.30 & NS & NS & 0.08 \\
\hline C18:1(n-9) & 22.8 & 23.4 & 20.5 & 25.1 & 0.37 & NS & NS & $<0.01$ \\
\hline C18:2(n-6) & 3.56 & 2.68 & 3.89 & 3.86 & 0.18 & NS & $<0.01$ & NS \\
\hline $\mathrm{C} 18: 3(n-3)$ & 0.44 & 0.31 & 0.46 & 0.37 & 0.01 & $<0.01$ & $<0.01$ & $<0.01$ \\
\hline$c-9, t-11$ CLA & 1.01 & 1.13 & 0.88 & 0.60 & 0.07 & NS & $<0.01$ & 0.03 \\
\hline C22:0 & 0.09 & 0.08 & 0.09 & 0.08 & 0.02 & NS & NS & NS \\
\hline C22:1 & 0.15 & 0.11 & 0.15 & 0.10 & 0.01 & $<0.01$ & NS & $<0.01$ \\
\hline Other & 6.98 & 7.65 & 6.55 & 7.37 & 0.35 & 0.02 & NS & NS \\
\hline
\end{tabular}

${ }^{1}$ Diets contained either $2.45 \%$ SBO, $2.75 \%$ calcium salts of SBO (CAS), $2.75 \%$ amides of SBO (AMD), or $2.75 \%$ blended fat (MIX) consisting of calcium salts and amides of SBO (80:20, wt/wt).

${ }^{2}$ Contrasts are designed as 1) SBO vs. other diets, 2) MIX vs. CAS and AMD, and 3) CAS vs. AMD.

tion of C18:1 (n-9) from AMD (Table 4). The proportion of all fatty acids from C4:0 to C16:0 (except C14:1) were lower for AMD than they were for CAS. This result agrees with Jenkins (1998) in which $3.5 \%$ oleamide fed to Holstein cows increased 18-carbon unsaturated fatty acids in milk and decreased medium- to short-chain fatty acids compared with canola oil. Milk concentrations of C4:0, C6:0, and C8:0 were low for all diets, which has been attributed to high volatility of the methyl esters (Jensen et al., 1991). The percentage of milk C18:2 $(n-6)$ was lower for MIX $(P<0.01)$ than it was for AMD or CAS. The MIX diet had the highest $(P$ $<0.01$ ) percentage of $c i s-9$, trans-11 CLA compared with the other protected fat supplements. The SBO diet produced the highest percentage of C18:0 compared with the other fat supplements, consistent with higher ruminal biohydrogenation for SBO vs. the protected supplements.

Milk yields were reduced $(P=0.09)$ by the protected fats compared with SBO, but did not differ for AMD vs. CAS. Fatty acid concentration (Table 2) was higher for AMD than for CAS, which presumably supplied greater energy to maintain milk production despite the lower DMI for AMD. Milk protein concentrations were not affected by diet.

\section{CONCLUSIONS}

In this study, biohydrogenation of dietary C18:2 ( $n$ 6 ) in lactating cows decreased slightly when a SBO supplement was converted to amides or calcium salts. Biohydrogenation of dietary C18:1 (n-9) also decreased slightly when the SBO supplement was fed to cows as calcium salts. Biohydrogenation of C18:1 (n-9) in the rumen decreased extensively when the SBO was added to the ration as amides. The soybean amide more than doubled the delivery of C18:1 (n-9) to the omasum of lactating cows. However, the soybean amide in this study also increased trans fatty acid production in the rumen, leading to milk fat depression, which was not observed in earlier studies for amides of high oleic acid fat sources.

\section{ACKNOWLEDGMENTS}

Approved as technical contribution no. 4902 of the South Carolina Agricultural Experiment Station, Clemson University. The authors gratefully acknowledge Evanne Thies for her assistance with fatty acid analysis. 


\section{REFERENCE}

Ahvenjarvi, S., A. Vanhatalo, P. Huhtanen, and T. Varvikko. 2000. Determination of reticulo-rumen and whole-stomach digestion in lactating cows by omasal canal or duodenal sampling. Br. J. Nutr. 83:67-77.

Ahvenjarvi, S., A. Vanhatalo, K. J. Schingfield, and P. Huhtanen. 2003. Determination of digesta flow entering the omasal canal of dairy cows using different marker systems. Br. J. Nutr. 90:41-52.

AOAC. 1990. Official Methods of Analysis. 15th ed. AOAC, Arlington, VA.

Baumgard, L. H., B. J. Corl, D. A. Dwyer, A. Saebo, and D. E. Bauman. 2000. Identification of the conjugated linoleic acid isomer that inhibits milk fat synthesis. Am. J. Physiol. Regulatory Integrative Comp. Physiol. 278:R179-R184.

Chouinard, P. Y., V. Girard, and G. J. Brisson. 1997. Lactational response of cows to different concentrations of calcium salts of canola oil fatty acids with or without bicarbonates. J. Dairy Sci. 80:1185-1193.

Chouinard, P. Y., V. Girard, and G. J. Brisson. 1998. Fatty acid profile and physical properties of milk fat from cows fed calcium salts of fatty acids with varying unsaturation. J. Dairy Sci. 81:471.

Doreau, M., and Y. Chilliard. 1997. Digestion and metabolism of dietary fat in farm animals. Br. J. Nutr. 78 (Suppl. 1):S15-S35.

Fotouhi, N., and T. C. Jenkins. 1992. Ruminal biohydrogenation of linoleoyl methionine and calcium linoleate in sheep. J. Anim. Sci. 70:3607.

Giesy, J. G., M. A. McGuire, B. Shafii, and T. W. Hanson. 2002. Effect of dose of calcium salts of conjugated linoleic acid (CLA) on percentage and fatty acid content of milk fat in midlactation Holstein cows. J. Dairy Sci. 58:2023-2029.

Griinari, J. M., D. E. Baumann. 1999. Biosynthesis of conjugated linoleic acid and its incorporation into meat and milk in ruminants. Pages 180-200 in Advances in Conjugated Linoleic Acid Research. M. P. Yurawecz, M. M. Mossoloa, J. K. G. Kramer, M. W. Pariza, and G. J. Nelson, eds. AOCS Press, Champaign, IL.

Griinari, J. M., D. A. Dwyer, M. A. McGuire, D. E. Bauman, D. L. Palmquist, and K. V. V. Nurmela. 1998. Trans-octadecenoic acids and milk fat depression in lactating dairy cows. J. Dairy Sci. 81:1251-1261.

Harfoot, C. G., and G. P. Hazelwood. 1988. Lipid metabolism in the rumen. Pages 285-322 in The Rumen Microbial Ecosystem. P. N. Hobson, ed. Elsevier Science Publishing, New York, NY.

Hristov, A. N., and J. K. Ropp. 2003. Effect of dietary carbohydrate composition and availability on utilization of ruminal ammonia nitrogen for milk protein synthesis in dairy cows. J. Dairy Sci. $86: 2416-2427$.
Huhtanen, P., P. G. Brotz, and L. D. Satter. 1997. Omasal sampling technique for assessing fermentative digestion in the forestomach of dairy cows. J. Anim. Sci. 75:1380-1392.

Jenkins, T. C. 1998. Fatty acid composition of milk from Holstein cows fed oleamide or canola oil. J. Dairy Sci. 81:794-800.

Jenkins, T. C. 1999. Lactation performance and fatty acid composition of milk from Holstein cows fed 0 to $5 \%$ oleamide. J. Dairy Sci. 82:1525-1531.

Jenkins, T. C., H. G. Bateman, and S. M. Block. 1996. Butylsoyamide increases unsaturation of fatty acids in plasma and milk of lactating cows. J. Dairy Sci. 79:585-590.

Jenkins, T. C., C. E. Thompson, and W. C. Bridges, Jr. 2000. Site of administration and duration of feeding oleamide to cattle on feed intake and ruminal fatty acid concentrations. J. Anim. Sci. 78:2745-2753.

Jenkins, T.C., E. J. Thies, and E.E. Mosely. 2001. Direct methylation procedure for converting fatty amides to fatty acid methyl esters in feed and digesta samples. J. Agric. Food Chem. 49:2142-2145.

Jenkins, T. C., and C. S. Adams. 2002. The biohydrogenation of linoleamide in vitro and its effects on linoleic acid concentration in duodenal contents of sheep. J. Anim. Sci. 80:533-540.

Jensen, R. G., A. M. Ferris, and C. J. Lammi-Keefe. 1991. The composition of milk fat. J. Dairy Sci. 74:3228-3243.

Kepler, C. R., W. P. Tucker, and S. B. Tove. 1970. Biohydrogenation of unsaturated fatty acids, IV. Substrate specificity and inhibition of linoleate $\Delta^{12}$-cis, $\Delta^{11}$-trans isomerase from Butyrivibrio fibrisolvens. J. Biol. Chem. 245:3612.

Klusmeyer, T. H., and J. H. Clark. 1991. Effects of dietary fat and protein on fatty acid flow to the duodenum and in milk produced by dairy cows. J. Dairy Sci. 74:3055-3067.

Kramer, J. K. G., V. Fellner, M. E. R. Dugan, F. D. Sauer, M. M. Mossoba, and M. P. Yurawecz. 1997. Evaluating acid and base catalysts in the methylation of milk and rumen fatty acids with special emphasis on conjugated dienes and total trans fatty acids. Lipids 32:1219-1228.

Reynal, S. M., and G. A. Broderick. 2003. Effects of feeding dairy cows protein supplements of varying ruminal degradability. J. Dairy Sci. 86:835-843.

SAS Users Guide: Statistics, Version 8, 18th ed. 2000. SAS Inst., Inc., Cary, NC.

Sukhija, P. S., and D. L. Palmquist . 1990. Dissociation of calcium soaps of long-chain fatty acids in rumen fluid. J. Dairy Sci. 73:1784-1787.

Van Soest, P. J., J. B. Robertson, and B. A. Lewis. 1991. Methods for dietary fiber, neutral detergent fiber, and nonstarch polysaccharides in relation to animal nutrition. J. Dairy Sci. 74:35833597.

Wu, Z., O. A. Ohajuruka, and D. L. Palmquist. 1991. Ruminal synthesis, biohydrogenation, and digestibilities of fatty acids by dairy cows. J. Dairy Sci. 74:3025-3034. 